Emina Dedić Bukvićl,

Lejla Hajdarpašićc

\title{
INFORMACIJSKA PISMENOST: SADRŽAJ PROGRAMA OBRAZOVANJA NASTAVNIKA/CA
}

\section{- Sažetak -}

Budući da informacijska pismenost omogućava stjecanje metakompetencija neophodnih za cjeloživotno učenje, njeni se sadržaji, na svjetskoj sceni posmatrajući, redovito i slijedom brojnih za obrazovni kontekst relevantnih međunarodnih smjernica, standarda $i$ sl., uključuju $u$ formalne te $i$ neinstitucionalne oblike obrazovanja svih nivoa. Kao krovna pismenost savremenogdoba, informacijska pismenostje nužno ineizostavna kompetencija nastavnika/nastavnica 21. stoljeća, što su programi Pedagoškog obrazovanja nastavnika (PON) realizirani na Filozofskom fakultetu Univerziteta u Sarajevu akademske 2011/2012. i 2012/2013. godine, uvođenjem sadržaja Informacijska pismenost, akcentirali. S tim u vezi, ovaj rad će propitati razloge zbog kojih se pomenuti sadržaj kandidirao kao neprijeporno važan segment $P O N-a$ te će opsežnu komparaciju očekivanih ishoda učenja sa stvarnim ishodima učenja proisteklu iz analize evaluacijskih listova koje su polaznici/polaznice prvog ciklusa PON-a popunjavali dopuniti nedostajućom kvalitativnom analizom evaluacijskih listova popunjenih nakon drugog ciklusa PON-a.

Ključne riječi: informacijska pismenost, cjeloživotno učenje, pedagoško obrazovanje nastavnika/nastavnica.

1 Emina Dedić Bukvić, Odsjek za pedagogiju, Filozofski fakultet Univerziteta u Sarajevu, dedic.emina@gmail.com.

2 Lejla Hajdarpašić, Odsjek za komparativnu književnost i bibliotekarstvo, Filozofski fakultet Univerziteta u Sarajevu, lejla.hajdarpasic83@gmail.com. 


\section{Uvod}

$\mathrm{Na}$ nastavnike se gotovo uvijek gledalo kao na osobe čija najvažnija djelatnost omogućava učinkovito osposobljavanje učenika za produktivno ponašanje $u$ postojećim i budućim promjenama. Tako se od škole i nastavnika očekuje učinkovito „postupanje s učenicima”, senzibilnost prema socijalnoj koheziji i toleranciji, učinkovito odgovaranje na potrebe učenika s poteškoćama, upotreba novih tehnologija te praćenje novih znanja i pristupa u ocjenjivanju učenika (Babić, 2007). Odnosno, nastavnici trebaju osposobiti učenike za kontinuirane društvene promjene i naučiti ih da znaju učiti, tj. motivirati ih za cjeloživotno učenje. Kako bi se ostvarili zahtjevi koje društvo postavlja pred nastavnike, neophodno je „odgovarajuće” obrazovanje učitelja.

Današnje škole su podložne brojnim promjenama i izazovima. To se ogleda i u novim ulogama nastavnika, koje naglašavaju spremnost i otvorenost za promjene. Naime, nastavnici gube neke tradicionalne uloge (više nisu jedini izvor znanja), prilagođavaju se savremenim prilikama i prihvataju neke nove uloge (inicijator, mentor, kreator odgojno-obrazovnog procesa itd.).

Ukoliko pokušamo sumirati i kategorizirati „nove” uloge nastavnika u savremenom odgojno-obrazovnom procesu, možemo uočiti slijedeće: nove strategije poučavanja i učenja, nove metode i sredstva u radu - s naglaskom na primjeni informacione tehnologije u nastavi, novim društvenim vrijednostima i normama koje zahtijevaju interkulturno, sigurno, poticajno i inkluzivno okruženje za rad i život u razrednoj i školskoj zajednici, sposobnostima za istraživanje, evaluaciji i refleksiji teorije i prakse, kao i potrebi za profesionalnim razvojem i cjeloživotnim učenjem.

\section{Pedagoško obrazovanje nastavnika na Filozofskom fakultetu Univerziteta u Sarajevu}

Filozofski fakultet u Sarajevu je jedan od članova Univerziteta u Sarajevu, koji organizira obrazovanje nastavnika u toku redovnog studija. Pored toga, osmišljava edukacijski proces pod nazivom Pedagoško obrazovanje nastavnika (PON), koje pohađaju polaznici zainteresirani za odgojno-obrazovni rad. Polaznici PON-a su prethodno završili bilo koji fakultet ili stručnu školu, te stekli diplomu za neku profesionalnu oblast (arhitektura, biologija, ekonomija itd.). Znači, polaznici PON-a imaju stručnu osposobljenost, ali ne i osposobljenost za nastavnički rad.

$\mathrm{Na}$ Odsjeku za pedagogiju Filozofskog fakulteta u Sarajevu educiraju se polaznici za odgojno obrazovni rad. 
Akademske 2011/2012. godine, Odsjek za pedagogiju je ponudio inovirani program $\mathrm{PON}-\mathrm{a}^{3}$. Ideja za inoviranje obrazovanja nastavnika proizašla je iz dva evropska dokumenta o obrazovanju. Jedan je OECD-ov program - Definition and Selection of Competencies: Teoretical and Conceptual Foundations (DeSeCo), koji definira ključne kompetencije za aktivno učešće u životu, a drugi je ISSA-ina lista pedagoških standarda kojima se definira kvalitet pedagoške prakse.

$\mathrm{Na}$ osnovu uvida u ishode učenja nakon izvedenog edukacijskog ciklusa u akademskoj 2011/2012. godini, Odsjek za pedagogiju je ponudio inovirani program pedagoškog obrazovanja nastavnika i u 2012/2013. godini.

Sadržaji edukacijskog ciklusa u 2012/2013. godini poštivaju prethodno postavljene kompetencije i standarde pedagoškog rada na PON-u(2011/2012.).

Cilj edukacijskog ciklusa je osposobljavanje stručnjaka različitih oblasti za rad u nastavi, za kreiranje pozitivne klime u razredu, uspješniju komunikaciju sa svim članovima odgojno-obrazovnog procesa, planiranje i realiziranje nastavnog procesa, osposobljavanje iz oblasti informacijske pismenosti itd.

Pomenute i druge kompetencije programa razvijat će se kroz sadržaje nastave PON-a. Program se realizira u toku 8 susreta, a obuhvata 128 sati, od kojih je 96 sati formalnog, a 36 sati informalnog učenja.

Odsjek za pedagogiju kao nositelj edukacijskog ciklusa po potrebi angažira kolege/kolegice s drugih odsjeka Filozofskog fakulteta u Sarajevu ili iz drugih organizacija koje se bave podukom i obrazovanjem nastavnika. $\mathrm{U}$ tom kontekstu, a prepoznajući u inoviranom programu informacijsku pismenost kao vrstu kvalitativnog pomaka i proširenja tradicionalne paradigme obrazovanja, koja se proširila od tradicionalne pismenosti (čitanje i računanje), do klastera pismenosti relevantnih za moderno društvo ${ }^{4}$, što je čini nezaobilaznim sadržajem u edukacijskom ciklusu koji nerijetko zahtijeva $\mathrm{i}$ interdisciplinarne aktivnosti, u realizaciji pomenutih ciklusa PON-a aktivno su učestovale kolege/kolegice s Odsjeka za komparativnu književnost i bibliotekarstvo Filozofskog fakulteta Univerziteta u Sarajevu.

3 Više u: Mavrak, Mirjana, Hajdarpašić, Lejla: Informacijska pismenost i pedagoško obrazovanje nastavnika/6. Savjetovanje o reformi visokog obrazovanja. Kontinuitet reforme visokog obrazovanja. Sarajevo, 13. i 14. april 2012. [rad u štampi].

4 Dizdar, Senada: Informacijska pismenost - metakompetencija za cjeloživotno učenje, 2012.

Dostupno na:http://unsa.ba/s/index.php?option=com content\&task=view\&id=1151\&Itemid=348\&lang=bosanski (11. 12. 2012.). 


\section{Informacijska pismenost kao važna kompetencija nastavnika/nastavnica}

Široki okvir kompetencija koji nudi DeSeCo omogućava uvažavanje vrijednosti društva u kojem se taj program primjenjuje. Tako vrijednosti kao što su: uspješan život kojem teži pojedinac, elementi koji se cijene u društvu (s naglaskom na informacijsko-informatičkoj kompetentnosti), poželjni obrasci ponašanja i drugo, omogućavaju identificiranje i selekciju ključnih kompetencija određenog društva.

Identifikacijom i selekcijom ključnih kompetencija nastavnika, pružaju se mogućnosti mladim naraštajima da lakše nauče kako se uspješno uključiti u socijalno heterogene, interkulturno obilježene grupe, kako bi imali nezamjenjive preduslove za uspješan individualni i održiv socio-ekonomski i demokratski razvoj u društvu.

Stoga je naglasak na pripremi novih generacija za život u savremenom društvu, a ne samo na savladavanju gradiva propisanog kurikulumom.

Da bismo pripremili mlade generacije za savremene društvene tokove, neophodno je dati poseban značaj obrazovanju nastavnika. Nastavnik/ nastavnica je, nema sumnje, pedagoški subjekt sposoban i spreman u drugom razvijati znanje i vrijednosti (Slatina, 2008). Jer niti jedna profesija ne ostavlja tako važne posljedice na budućnost društva kao profesija nastavnika.

Temeljem ovih promišljanja, ukazuje se na iznimnu potrebu informacijskog opismenjavanja mladih naraštaja. Informacijska pismenost predstavlja ključ promoviranja koncepcije društva koje uči i koncepta cjeloživotnog učenja.

Time se ističe nužna potreba nastavnika za stjecanjem kompetencija za primjenu informacijsko-komunikacijskih tehnologija u nastavi, kao i u drugim elementima odgojno-obrazovnog rada. Ovom pismenošću nastavnik/ nastavnica je u mogućnosti ispuniti zahtjeve za cjeloživotnim učenjem, te pokazati i prenijeti na mlade vještine kao što su korištenje računara za traženje, prikupljanje, pohranu, prezentiranje podataka i informacija, umrežavanje, omogućavanje približavanja obrazovanja mjestu učenja tako što se kreiraju programi za učenje na daljinu, modeliranje računarskih didaktičkih programa itd.

Evropski dokumenti naglašavaju ozbiljnost ove kompetencije. Međutim, polaznici prethodnog i ovogodišnjeg edukacijskog ciklusa prilikom definiranja obrazovnih potreba uopće ne uviđaju informacijsku pismenost kao jednu od ključnih kompetencija. Ovaj podatak predstavlja bogat materijal u edukacijskom ciklusu, u procesu evaluacije i u procesu refleksije pedagoškog obrazovanja nastavnika. 


\section{Informacijska pismenost kao sadržaj PON-a}

Posljednjih je desetljeća za koncept informacijske pismenosti znanstveni diskurs iznjedrio najraznolikije generičke ili specifične modele, standarde informacijske pismenosti, te definicije koncepta u setu kojih je ALA-ino (engl. American Library Association) tumačenje informacijske pismenosti najšire prihvaćeno. ALA informacijsku pismenost definira kao popis kompetencija, a informacijski pismene osobe kao one koje su „naučile kako učiti, kao one koje znaju kako učiti jer znaju kako je znanje organizovano, one koje znaju kako pronaći informacije i kako ih koristiti na svima razumljiv način"s. Osim popisa vještina neophodnih za preživljavanje u savremenom kompleksnom okruženju, informacijska se pismenost nerijetko definira i kao fenomen koji je u kauzalnoj vezi sa širim socijalnim i kulturnim kontekstom, a koji „osposobljava ljude da u svim segmentima života traže, vrednuju, koriste i stvaraju informacije učinkovito kako bi dosegli svoje lične, društvene, profesionalne i obrazovne ciljeve" kako je to istaknuto, recimo, u Aleksandrijskom proglasu o informacijskoj pismenosti $i$ cjeloživotnom učenju. Pomenutim i brojnim drugim jednako značajnim tumačenjima koncepta zajedničko je ne samo razumijevanje informacijske pismenosti kao koncepta koji je sine qua non savremenog informacijskog okruženja već i spoznaja o tome da je ideja cjeloživotnog učenja kao fenomen u neraskidivoj vezi s ovim konceptom, te da je koleracija informacijske pismenosti i obrazovanja posebno snažna. Ova je neraskidiva veza postala predmetom brojnih nacionalnih i međunarodnih inicijativa, između ostalog i zbog rastuće prisutnosti informacijsko-komunikacijskih tehnologija u obrazovnim procesima, pojave novih teorija obrazovanja te je u informacijski zrelim zajednicama zaokupljenost pomenutom korelacijom rezultirala uključivanjem sadržaja informacijske pismenosti u nastavne planove i programe svih nivoa obrazovanja. S tim u vezi S. Špiranec i M. Banek Zorica (2008.) posve legitimno zaključuju da obrazovne ustanove koje imaju ugrađene integrirane sadržaje za informacijsko opismenjavanje u planove i programe mogu za sebe reći da imaju kurikulum za 21. stoljeće, nastavni plan i program primjeren zahtjevima društva znanja, ali i da je tek ispreplitanjem

5 ALA. Presidential Committee on information literacy: Final report. 1989.

URL: http://www.ala.org/ala/mgrps/divs/acrl/publications/whitepapers/presidential.cfm (10. 8. 2010.).

6 The Alexandria proclamation on information literacy and lifelong learning. National Forum on information literacy, 2005.

URL: http://portal.unesco.org/ci/en/ev.phpURL ID=20891\&URL DO=DO TOPIC\&URL $\underline{\text { SECTION=201.html }}$ (10. 8. 2010.). 
informacijske pismenosti i kurikularnih sadržaja, strukture i slijeda, moguće postići sustavnost u razvoju vještina višeg reda i završnog cilja informacijske pismenosti, a to je učiti kako učiti. U tom kontekstu posmatrajući, uspješnost programa informacijske pismenosti u primarnom i sekundarnom obrazovanju očito je najprije determinirana partnerskim odnosima na relaciji između nastavnika/nastavnica i informacijskih stručnjaka/stručnjakinja, osviještenosti nastavnog i bibliotečkog osoblja o značaju informacijskog opismenjavanja i njihovoj spremnosti da aktivno učestvuju u strukturiranju te realizaciji programa informacijskog opismenjavanja u školskom okruženju? Da bi nastavnici/nastavnice (i/ili bibliotekari/bibliotekarke) 21. stoljeća mogli punim kapacitetom pomoći realizaciju sadržaja informacijske pismenosti, oni najprije moraju biti upoznati sa svim aspektima i zakonitostima ovoga koncepta. Jedino tako mogu aktivno učestvovati u procesima konstrukcije znanja učenika u savremenoj informacijskoj okolini koju karakterizira kompleksni spoj analognih i digitalnih izvora informacija, a čija učinkovita upotreba zahtijeva da se temeljne (bibliotečke) vještine pronalaženja i pristupa izvorima informacija obogate kompetencijama evaluacije i učinkovite upotrebe informacija, na što su, uostalom, i upozorile nove teorije obrazovanja u setu kojih je, recimo, konstruktivistička paradigma učenja osobito reprezentativna. Konstruktivizam, pedagoški moderni pristup, informaciju i onoga ko uči stavlja u centar procesa učenja te ulogu nastavnika/nastavnice u procesu učenja, u odnosu na tradicionalni pristup, tumači bitno drugačije: nastavnik/nastavnica treba naučiti učenike kako da uče (learning to learn). Za konstruktivizam je očito karakterističan samostalan rad i interakcija pojedinca s informacijskim izvorima, za što taj isti pojedinac treba steći određene vještine i sposobnosti, poput pretraživanja i pronalaženja informacijskih izvora, njihove selekcije i analize, što informacijsku pismenost pozicionira u samo srce konstruktivističkog pristupa učenju (Banek Zorica, M.; Špiranec, S., 2008: 7). Uvažavajući obaveze i odgovornosti obrazovnih institucija i njihovih nastavnika, PON 2012/2013. (kao i njegov prethodnik PON 2011/2012.) je sadržaj Informacijska pismenost prepoznao kao važan

7 Prema opsežnom istraživanju M. C. Rojtas-Milliner, najčešće su prepreke u realizaciji programa informacijskog opismenjavanja u školskom okruženju prouzrokovane upravo neadekvatnim poznavanjem koncepta informacijske pismenosti od strane nastavnika i bibliotekara, a oni koji ne žele podržati uvođenje programa informacijskog opismenjavanja, informacijsku pismenost poistovjećuju s informatičkom pismenošću, imaju nedovoljna pedagoška znanja (bibliotekari) i sl. Rojtas-Milliner, Mary C. Hey: Ova školska biblioteka nije što je nekada bila: proces promjene i sociopolitička stvarnost implementacije kurikularno integriranog srdenjoškolskog programa informacijske pismenosti. Disertacija. Univerzitet u Pittsburghu: Fakultet obrazovanja. 2006.

URL: http://d-scholarship.pitt.edu/6848/1/main-file-etd-04072006-142901.pdf (24.12.2012.). 
segment programa pedagoškog obrazovanja nastavnika/nastavnica 21. Stoljeća, odnosno informacijsku pismenost kao metakompetenciju neophodnu za cjeloživotno učenje.

\section{Struktura i ciljevi novouvedenog sadržaja}

U osmišljavanju programa informacijskog opismenjavanja, pitanje kome je namijenjen program određuje i kako će se i na koji način program strukturirati, informacijska pismenost je prvenstveno kontekstom ovisan koncept i u tom smislu se tokom djelimičnog preoblikovanja PON-a 2012/2013. kao i PON-a 2011/2012. strogo vodilo računa o kontekstu u kojem se sadržaj Informacijska pismenost ima realizirati. Izbjegavajući redundanciju, uvažavajući heterogenost u pogledu stečenih znanja i interesa polaznika/polaznica, te akcentirajući najprije praktičnu obuku, sadržaj Informacijska pismenost se realizirao u tri veća nastavna bloka u kojima se koncept informacijske pismenosti sagledavao kroz spektar nekoliko tema ${ }^{8}$, a kojima su se anticipirali, između ostalog, sljedeći ishodi učenja:

- razumijevanje promjena koje su se desile u obrazovnom procesu,

- savladavanje i prenošenje vještina na kojima počiva informacijska pismenost,

- savladavanje vještina potrebnih za vrednovanje informacija i informacijskih izvora,

- praktično savladavanje izrade znanstvenog i stručnog rada sa svim relevantnim elementima,

- savladavanje tehnika, strategija pretraživanja informacija u okruženju vidljivog i nevidljivog weba,

- razumijevanje koncepta Mreže kao nove paradigme društvenih odnosa,

- osvještavanje o važnosti promoviranja, kreiranja i upotrebe otvorenih obrazovnih resursa i sl.

S ciljem kvalitativnog uvida u stvarne ishode učenja izvedene nastave i njihova kompariranja s navedenim očekivanim ishodima učenja, polaznici/ polaznice sadržaja Informacijska pismenost realiziranog akademske 2011/2012. godine ispunjavali su anonimne ,3, 2, 1” evaluacijske listiće sačinjene od tri pitanja:

8 Informacijska pismenost - metakompetencija za cjeloživotno učenje, Informacijsko čitanje, Problematika informacijskog pretraživanja vidljivog i nevidljivog Weba, Evaluacija informacija i informacijskih izvora, Informacijska etika - društveno odgovorno upravljanje (mrežnim) informacijama, Otvoreni obrazovni resursi (Open Educational Resources - ORL) i copyleft licenciranje. 
1. 3 ,stvari” iz današnje edukacije koje ste zapamtili

2. 2 ,stvari” iz današnje edukacije o kojima biste željeli saznati više

3. 1 ,stvar" koju ćete odmah primijeniti u profesionalnom ili svakodnevnom životu

Kvalitetna analiza popunjenih evaluacijskih listića otkrila je zanimljive strukturalne ponovljivosti u odgovorima na ponuđena pitanja u sva tri bloka nastave ponaoso $b^{9}$. Kvalitativni pokazatelji potvrdili su da stvarni ishodi učenja izvedene nastave $\mathrm{u}$ velikoj mjeri korespondiraju $\mathrm{s}$ antipiciranim ishodima učenja, a posebno su bili ohrabrujući kvalitativni pokazatelji o planiranoj primjeni i prenošenju stečenih informacijskih kompetencija polaznika/ polaznica PON-a 2011/2012. Kao i njihovi prethodnici, polaznici/polaznice sadržaja Informacijska pismenost realiziranog akademske 2012/2013. godine su anonimno popunjavali evaluacijske listiće pomenute strukture, o čijoj će kvalitativnoj analizi, koja će se dovesti i u kontrast s analizom urađenom nakon prvog ciklusa PON-a, biti više riječi u nastavku.

\section{Kvalitativna (komparativna) analiza evaluacijskih listića ,3,2,1”}

Nakon sva tri bloka pomenute nastave, popunjeno je ukupno 40 evaluacija ,3,2,1" u cijelosti ili djelimično (što odgovara broju polaznika/ polaznica PON-a 2012/2013). U vezi s prvim pitanjem (3 ,stvari” iz današnje edukacije koje ste zapamtili), većina polaznika/polaznica navodi da koncept informacijske pismenosti sagledava kroz prizmu razlikovanja informacijske pismenosti i informatičke pismenosti, da su upoznati s tehnikama pretraživanja vidljivog ( $\mathrm{f}=31)$ te nevidlivog weba $(\mathrm{f}=26)$, sa CC-om $(\mathrm{f}=20)$ te autorskim i drugim srodnim pravima $(\mathrm{f}=25)$. U ponuđenim se odgovorima očito ima prepoznati korespondencija između očekivanih te stvarnih ishoda učenja. Gledajući ove strukturalne ponovljivosti u odnosu na odgovore ponuđene nakon prvog edukacijskog ciklusa, gdje su ispitanici/ispitanice navodili kako pamte razliku između informacijske pismenosti i informatičke pismenosti ( $\mathrm{f}=26)$, ali $\mathrm{i}$ informacijskog društva i društva znanja $(\mathrm{f}=10)$ te navode da su upoznati s tehnikama pretraživanja vidljivog/nevidljivog weba ( $\mathrm{f}=33$ ), pojmovima copyleft $(\mathrm{f}=24)$ i copyright $(\mathrm{f}=14)$ i sl.; može se primijetiti kako su polaznici/polaznice oba ciklusa upravo kroz pomenute zapamćene stvari najprije osviješteni o razlici između informacijske i informatičke pismenosti

9 Više o tome: Mavrak, Mirjana. Hajdarpašić, Lejla: Informacijska pismenost i pedagoško obrazovanje nastavnika/6. Savjetovanje o reformi visokog obrazovanja. Kontinuitet reforme visokog obrazovanja. Sarajevo, 13. i 14. april 2012. [rad u štampi]. 
(informacijska pismenost podrazumijeva podučavanje tzv. višim vještinama, vještinama pretraživanja, vrednovanja, etična korištenja, usporedbe i učinkovite upotrebe informacija), što se ima prepoznati kao posebno značajno, a zatim i upoznati s nekim temeljnim kompetencijama koje ovaj koncept podrazumijeva, što također ohrabruje.

U odgovorima na drugo pitanje (2, ,stvari” iz današnje edukacije o kojima biste željeli saznati više), većina ispitanika/ispitanica navodi kako bi voljeli znati nešto više o, naprimjer, pretraživanju nevidljivog/vidljivog weba (f=19) ili CC-u i autorskim pravima ( $\mathrm{f}=10)$. O tom, veće je frekvencije pojavljivanja utvrdila analiza evaluacijskih listića prvog edukacijskog ciklusa. Naime, analiza ponuđenih odgovora je otkrila kako bi ispitanici/ispitanice voljeli znati nešto više o realizaciji programa informacijske pismenosti u Bosni i Hercegovini, specijaliziranim bazama podataka i metapretraživačima $(\mathrm{f}=16)$, o CC licencama $(\mathrm{f}=14)$ itd. Pomenute bi se frekvencije mogle opravdati razlikom u broju polaznika/polaznica prvog i drugog ciklusa PON-a ili naprosto zadovoljstvom polaznika/polaznica drugog edukacijskog ciklusa ponuđenim temama iz sva tri bloka nastave.

Odgovori koji se u trećem pitanju (1 „stvar” koju ćete odmah primijeniti u profesionalnom ili svakodnevnom životu) strukturalno ponavljaju, vidno pokazuju da će ispitanici primijeniti stečene kompetencije koje se u najvećem broju odnose na tehnike pretraživanja vidljivog/nevidljivog weba $(\mathrm{f}=21)$, te $\mathrm{CC}$ i autorska prava ( $\mathrm{f}=16)$, što je zastupljeno i u odgovorima koje su na ovo pitanje i polaznici/polaznice prvog ciklusa ponudili. Ipak, polaznici/ polaznice prvog edukacijskog ciklusa su u odgovorima na treće pitanje kao važno prepoznali i prenošenje stečenih kompetencija, navodeći da, recimo, planiraju ohrabriti učenike da koriste slobodne softvere, upoznati ih s kriterijima za evaluaciju izvora informacija, uputiti ih u načine pravilnog organiziranja literature i sl.

$\mathrm{Na}$ temelju ove nevelike kvalitativne (komparativne) analize može se primijetiti kako ponovo i ponajviše ohrabruju kvalitativni pokazatelji o planiranoj primjeni stečenih informacijskih kompetencija polaznika/ polaznica PON-a 2012/2013. Pomenuta primjena očito počiva na pretpostavci da polaznici/polaznice razumijevaju informacijsku pismenost kao metakompetenciju neophodnu za cjeloživotno učenje, da su osviješteni o ulozi informacijskih stručnjaka u realizaciji programa informacijske pismenosti, da uvažavaju preoblikovane, proširene zadaće i kompetencije nastavnika/nastavnica i sl. 


\title{
Zaključna razmatranja
}

Osmišljavanjem programa informacijskog opismenjavanja, obrazovne institucije mogu odigrati značajnu ulogu ne samo u promoviranju značaja konceptainformacijskepismenostiveć seiu ambiciji prelaska izinformacijskog društva u društvo znanja pojavljuju kao važne karike koje mogu ubrzati proces pomenute transformacije. S tim u vezi i na temelju rezultata kvalitativne analize popunjenih evaluacijskih listića posve je legitimno zaključiti kako se uključivanjem sadržaja Informacijska pismenost u PON 2012/2013., ali i PON 2011/2012. akademske godine ostvarilo nekoliko suštinskih pomaka:

- demonstrirale su se prednosti interdisciplinarnog proaktivnog reagovanja na novonastale promjene u obrazovnoj sferi;

- uspješno se promovirala relevantnost koncepta informacijske pismenosti u promijenjenoj kompleksnoj informacijskoj sredini;

- osvijestilo se o potrebi prenošenja stečenih kompetencija u profesionalnom i privatnom životu polaznika/polaznica PON-a, o čemu svjedoči velika korespondencija između očekivanih i stvarnih ishoda učenja.

\section{INFORMATIONAL LITERACY: CONTENT OF THE PROGRAMME FOR EDUCATION OF TEACHERS}

\begin{abstract}
- Abstract -
Information literacy enables acquisition of metacompetences that are necessary for lifelong learning. Consequently and in accordance to a number of relevant international guidelines, standards, etc. for educational context, information literacy contents are regularly included in the formal and noninstitutional forms of education. As an umbrella literacy of contemporary age, information literacy is a necessary and indispensable competency of teachers of the 21st century that Pedagogical Training of Teachers Programs (PON) implemented at the Faculty of Philosophy in Sarajevo in 2011/2012 and 2012/2013 with the introduction of content of Information literacy had emphasized. In this regard, this paper will examine the reasons why the aforementioned content ran as indisputable segment of PON and will supplement the extensive comparison of the expected learning outcomes with actual learning outcomes obtained from the analysis of evaluation sheets that
\end{abstract}


the participants of the first cycle PON filled with the qualitative analysis of evaluation sheets completed after the second cycle of PON.

\section{Key words: information literacy, lifelong learning, pedagogical training of teachers.}

\section{Literatura:}

- ALA. Presidential Committee on information literacy: Final report (1989) URL: http://www.ala.org/ala/mgrps/divs/acrl/publications/whitepapers/ presidential.cfm (pristup 10. 8. 2010.).

- Dizdar, S. (2008) Informacijska pismenost i cjeloživotno učenje u: Zbornik radova: II savjetovanje visokog obrazovanja - primjena Bolonjskih principa na Univerzitetu u Sarajevu.

- Lau, Jesus. International guidelines on information literacy (2004). Dostupno na: http://bivir.uacj.mx/dhi/DoctosNacioInter/Docs/Guidelines. pdf (10. 8. 2010.)

- OECD (2007) Definition and selection of Competencies: Teoretical and Conceptual Foundations (DeSeCo): Key Competencies for Successful Life and a Well - Functioning Society - Summary of final report; OECD.

- OECD (2001) Definition and selection of Competencies: Teoretical and Conceptual Foundations (DeSeCo):Background Paper.

- Rojtas-Milliner, Mary C. (2006) Hey this school library isn't what it used to be: the change process and the sociopolitical realities of implementing a curricularly integrated high school information literacy program. Dissertation. University of Pittsburgh: School of education. Dostupno na: http://d-scholarship.pitt.edu/6848/1/main-file-etd-04072006-142901.pdf (24.12.2012.).

- Slatina, M. (2008) Razvoj profesionalnih kompetencija univerzitetskih nastavnika u bolonjskom procesu, u: Zbornik radova: II savjetovanje Reforma visokog obrazovanja - primjena Bolonjskih principa na Univerzitetu u Sarajevu, str. 151-165.

- Špiranec, Sonja; Banek Zorica, Mihaela (2008) Informacijska pismenost: teorijski okvir i polazišta. Zagreb: Zavod za informacijske studije Odsjeka za informacijske znanosti Filozofskog fakulteta Sveučilišta u Zagrebu.

- The Alexandria proclamation on information literacy and lifelong learning (2005). National Forum on information literacy. Dostupno na: http://portal.unesco.org/ci/en/ev.phpURL ID =20891\&URL DO=DO TOPIC\&URL SECTION=201.html (10. 8. 2010.). 